\title{
An Analysis of Student's Ability in Understanding English Idiomatic Expressions for Speaking
}

\author{
Muhammad Chairul Aris ${ }^{1 *}$ \\ ${ }^{1}$ Department of English Language Studies, Universitas Hasanuddin, Makassar, Indonesia \\ *muhchairularis@gmail.com
}

\begin{abstract}
The aim of this research is to describe the student's ability in understanding English idiomatic expressions and to elaborate analysis upon the student's perception in understanding English idiomatic expressions. The method of this study was quantitative and qualitative. The writer collected the data by giving the test to the students which consist of 20 multiple choice tests and a questionnaire regarding their perspective about idiomatic expression, counting the errors that students made in the test then classified the result of students based on five criteria in methodology, summarized the perspective of students in understanding idiomatic expressions for speaking. Then put it in the data with the explanation. The result of this study shows that English department students batch 2017 at Hasanuddin University are enough in figuring out English idiomatic expressions and it can be categorized as "fair", with a total percentage of $57 \%$. The data shows that only one student got 'Very Good' with the percentage of $81-100 \%$, Ten students got 'Good' with the percentage $61-80 \%$, fifteen students got 'Fair' with the percentage of $41-60 \%$, three students got 'Bad' with the percentage of $21-40 \%$ and one student got 'Very Bad' with the percentage of $0-20 \%$. Based on the questionnaires given to the students regarding this test, most of the students claimed that English Idiomatic is very important to learn and quite hard to be learned due to contradicted meaning to what it has been written. For all these consequences, it is really recommended for the lecturers and departments to put this material as additional discussion or material in learning Programme to help students have deeper understanding about idiom.
\end{abstract}

Key words: Case study, idiomatic expression, speaking sbility, student.

\section{Introduction}

English is an international language and has become one of the most important languages to everyone in the world. This language helps people to communicate with each other even if they come from different countries because English is officially adopted as an international language, English has been recognized as a tool for communication with all speakers of another language in place where English is not the first language but as a country which applies English as a foreign language, the learners need to master the language not only in terms of how English is used but also the way English native speakers use the language.

One of the most interesting and important things that English native speakers always use is "Idiomatic Expressions" as their strategy to communicate because it is used not only in formal ways but also in informal situations, 
especially in daily conversations. In addition, English idiomatic words are also in many things such as novels, newspapers, poems and etc.

The aim of learning and mastering idiom is to understand the meaning of idiom based on context to get a complete comprehension of the context of those phrases. Sometimes students translate the text word by word and idiom cannot be translated word by word, because idioms have their own meaning compared to other sentences and this is important for everyone to master it, moreover, it can be said that idiom is a sequence of words which has contradicted meaning as a group from the real meaning it if you figure out it from each word separately. Idioms show color to one language, helping us a lot emphasize meaning and to create our observations, judgments, and explanations livelily and interesting,

Mastering idioms is like mastering vocabulary. Vocabulary cannot be mastered and understood if students do not know the meaning and this is especially the same as idioms. There are a variety of idioms dictionaries such as McGraw-Hill's American idioms dictionary, Oxford Dictionary of English Idioms. Besides, the internet is the easiest and fastest way to get the meaning of idiom, Newspapers, magazines, radio programs. Television shows and films are also sources of idioms. Roleplaying, writing and interactive activities such as matching the parts of idioms are some activities that can help non-native speaker expand their knowledge and use of idioms.

The language users can translate the idiom in many ways and in several meanings but sometimes, it is untranslatable. The reasons that the students often translate the source language literally, without paying attention to the principles of source and target language are they do not understand the content of the target language are they do not understand the content of the target language, and difficult to find an equivalent word in the source language. Consequently, In translating an idiom the variety of meanings have to be Interpreted to find out the actual meaning of the idiom depending on the social and cultural context of the source language.

Based on the above reasons, the writer is interested to analyze the topic of the following title "An analysis of students ability in understanding English idiomatic expression for speaking, A case study at students of English department, Faculty of cultural science at Hasanuddin University batch 2017" This research, explores the quality of English department students in understanding idiomatic words.

\section{Theoretical Reviews}

\section{Definition of Idiom}

There are many expert perspectives regarding Idiomatic expressions. Newmark gives his perspective about idioms that the 'word' idiom consists of three senses to be mixed by natural tendency. Firstly, the idiom is the group of words whose meaning is unpredictable and contradicted the meaning of the constituent words. Secondly, the use of linguistics that is natural for native speakers of a language. Thirdly, the use of idioms by everyone and characteristics of vocabulary. However, to understand the meaning of idioms, the learners cannot translate the meaning of the idiomatic words directly because the meaning of the idiom can be interpreted by interrelating the idioms [1]. For instance, if the students translate the sentence or expression that contains idiom in "sometimes your brother can be a pain in the neck for me" word by word then it will lead to unusual meaning, but when the idiom is translated as a whole sentence then it can be interpreted as "sometimes your brother can be a trouble for me". An idiom is a phrase or sentence whose meaning is not clear from the meaning of its individual words and which must be learned as a whole unit, for instance, the idiom "spill the beans" means to reveal secret information, especially without intending to do so [2].

It also added that idiom is a sequence of words that cannot be interpreted word by word, they have meanings that are very different from the meaning of every word [3]. It can be said Idiom has a new meaning which cannot be interpreted literally because it will change the meaning of the idiom. The meaning of idiom can be understood through understanding the whole words [4]. Another expert also said that idiom is an ambiguous term, used in conflicting ways. "Inlay or general use, the idiom has two main meanings. The first, idiom is a particular manner of expressing something in the language, music, art, and soon. They characterize a person or group. The second, an idiom is a particular lexical collocation or phrasal lexeme, peculiar to a language.

From the definitions of idioms mentioned above, it can be concluded that an idiom is a group of words that have different meanings from the individual word as part of it. It cannot be translated word by word, but the meaning of the idiom is the meaning of a whole word. Idioms are sometimes irrational and ungrammatical, but other idioms are rational and fixed grammatical. It can be understood by guessing from the context.

\section{Types of Reading Comprehension}

There are two 'idiomaticity areas' in English, are the lexemic and the sememic [5]. The lexemic idiomaticity is an expression that consists of more than one word, which is subject to a possible lack of understanding, despite the clarity with the meanings of the components or the erroneous decoding: they can potentially mislead the uninformed listener. The sememic idiomaticity area involves expressions with more than one word, which have both logical 
literal meaning and a moral or a deeper meaning. It has been stated that lexemic idioms are categorized into 6 groups [6]:

First of all, Phrasal verbs Idioms. A phrasal verb is a verb that consists of two kinds of words. The first one is the verb and the second one is the particle. For instance: give up, cut back, get out, look forward and etc.

Secondly, tournure idioms. Tournure idioms are the largest lexemic idioms, usually containing at least three words and most of them are verbs. A tournure idiom mostly falls into a sentence. Based on the formula, tournure idioms can be classified into:

- The form contains compulsory definite and indefinite articles. For instance: to do a guy (to disappear secretly)

- The form contains an irreversible binomial introduced by a preposition. For instance: to be at seven and eight (to be in a condition of confusion, at odds)

- A direct object and further possible modifiers follow the primary verb. For instance: to build a castle in the air (to make impossible plans)

- The leading verb is not followed by a direct object but by the preposition plus or nothing. For instance: to dance on air (to get hanged).

Furthermore, Irreversible binomial idioms. Irreversible binomial idioms consist of two words, which are separated by a conjunction. The words orders in this formula are fixed. For instance: High and Dry (without resources), Romeo and Juliet (Institutionalizedsymbols of ideal love or symbol of true love).

In addition, Phrasal compound Idioms. Phrasal compound idioms are containing primarily nominal made up of adjectives plus nouns, noun plus nouns, verbs plus nouns, or adverbs plus prepositions. For instance: blackmail (any payment forced by intimidation), bookworm (a person committed to reading or studying).

Moreover, incorporating verbs idioms. Incorporating verbs idioms have the forms are noun-verb. Adjective-noun, noun-noun, adjective-noun. Usually incorporating verb separated by (-).

- Noun-verb, for instance: Sight-see means "visit the famous place in a city, country and etc."

- Adjective-Noun, for instance: Blackmail means "the crime of demanding money from a person by treating to tell somebody else a secret about them."

- Noun-Noun, for instance: bootleg means "make and sold illegally"

- Adjective-verb, for instance: whiteish means "an attempt to hide unpleasant facts about somebody/something."

\section{Factors of Idiom Comprehension}

It is essential to understand that idiom comprehension consists of three major factors such as transparency, familiarity, and context. First, Transparency is the degree of agreement between the literal and figurative meanings of an idiom [7]. The meaning of a transparent idiom matches well with the image it describes. An idiom like "go by the book" is highly transparent because of its literal meaning. To follow directions in a book exactly is closely associated with its nonliteral meaning, to closely follow rules and regulations but the expression "beat around the bush" is not transparent because its literal meaning is not associated with its nonliteral meaning, reluctance to talk about a topic. Semantic transparency is not a fixed and absolute feature. Second, familiarity is the frequency of occurrence of an idiom in the language. While an idiom such as "piece of cake" is frequently used in English. Another idiom like "get your wires crossed" is one that is rarely used. High-familiarity idioms are easier to understand than those of low familiarity. Lastly, The third major factor influencing idiom comprehension is context. Idiomatic expressions are understood in relation to the context in which they are used. As a result, the skills used to process and understand language in context are thought to be important for the development of idiom understanding.

\section{Methodology}

\section{Design}

This research employed qualitative and quantitative methods. Qualitative research is empirical research where the data are not in form of numbers whereas quantitative research is in form of numbers [8]. Quantitative research is specific in its surveying and experimentation process because it develops upon existing theories [9].

\section{Setting}

The research was conducted in the English Department of Hasanuddin University. It is located on Jln. Perintis Kemerdekaan KM.10. This research was conducted in September 2019. 


\section{Population}

The population of this research was the students of the English department batch 2017 from the Cultural sciences faculty at Hasanuddin University which consists of 107 students based on administration staff's information. They were chosen as research objects because they generally had learned about speaking and since in the first semester.

\section{Sample}

From the population above, The writer took 30 of English department Batch 2017 as the sample of this research. i.e $25 \%$ of all population. The students who became the sample were taken randomly without considering the academic achievement or English proficiency and also based on their willingness to participate in this research.

\section{Data Collection}

The instruments of research were:

\section{Library Research}

Library research is the way of collecting secondary data because the primary data has been collected by the author of those secondary data such as writers and researchers. In this case, the writer needs some books, journals, essays, and research results related to the problems being studied to have references and guidance's in explaining the data.

\section{Field Research}

To support this research, the writer used field research in order to get a lot of information and data that relevant to this study. In collecting data, the writer used the following techniques:

Test

In this part, the writer gave 20 multiple choice questions about English idiomatic expressions. There are four choices for each question to be chosen by the students to guess the meaning of the underlined sentences. One of the choices is the correct answer.

The writer used a descriptive approach in order to know the criteria of the students of the English department of Hasanuddin University Batch 2017., based on the result of the test. there are five criteria of students based on the percentage of the result of this test [10], they are :

- Very Good 81 - 100

- Good $61-80$

- Fair $41-60$

- Bad $21-40$

- Very Bad 0 - 20

Every student was given a score according to the criteria above and the mean score also used these criteria to get the conclusion of this research.

\section{Questionnaire}

The writer also used a questionnaire as an additional method of this research which consists of 3 simple questions that need to be answered by students. This question is to find out the student's difficulties and perspective in understanding Idiomatic expressions so that we can correlate between the result and the factors of getting that result.

\section{Data Analysis}

In this method, the writer analyzed data that is, the result of the tests which were given to the Respondents by using quantitative and qualitative analysis because the data was quantified with generating numerical data or data that can be transformed into usable statistics and gained opinions or reasons from respondents which finally be summed up.

There are several steps in analyzing data as follows;

Step one : Studying all the data, which were collected through tests and questionnaires.

Step two : The writer categorized the data according to the objective of this research.

Step three : Percentage data by calculating the number of the correct answer and the wrong answer and concluding student's perspective about English Idiomatic expression, in order to know the ability and the error of the students in understanding idiomatic expressions and the answers of questionnaires are be summed up by the writer to know students perspective about Idiom. To count the percentage of every student, the writer used this pattern. 


$$
P=\frac{F \chi}{N} \times 100
$$

Where :

$\mathrm{P}=$ Presentation of score

$\mathrm{Fx}=$ the frequency of all answers

$\mathrm{N}=$ total number of test

After that, the writer also counted the mean score:

$$
M=\frac{F}{N} \times 100
$$

Where :

$\mathrm{F}=$ sum of the total score

$\mathrm{N}=$ total of population

$\mathrm{M}=$ mean score

Step four : Tabulation of the result of the tests will be put into the table.

\section{Findings and Discussion}

\section{Findings}

The Data Presentation of Multiple-Choice Test in Understanding Idiomatic Expression

\begin{tabular}{|c|c|c|c|c|c|c|c|c|c|c|c|c|c|c|c|}
\hline \multirow[b]{2}{*}{ Question } & \multicolumn{15}{|c|}{ Student(Respondents) } \\
\hline & A & B & C & D & $\mathrm{E}$ & $\mathrm{F}$ & G & $\mathrm{H}$ & 1 & J & $\mathrm{K}$ & $\mathrm{L}$ & $M$ & $\mathrm{~N}$ & 0 \\
\hline 1 & 0 & 1 & 0 & 1 & 0 & 1 & 0 & 0 & 0 & 1 & 1 & 1 & 0 & 0 & 1 \\
\hline 2 & 0 & 1 & 0 & 0 & 1 & 1 & 0 & 1 & 0 & 0 & 0 & 0 & 0 & 1 & 0 \\
\hline 3 & 1 & 1 & 0 & 0 & 1 & 1 & 1 & 1 & 0 & 1 & 1 & 1 & 0 & 1 & 1 \\
\hline 4 & 1 & 0 & 0 & 0 & 0 & 0 & 0 & 0 & 0 & 0 & 1 & 1 & 0 & 1 & 1 \\
\hline 5 & 0 & 0 & 0 & 0 & 0 & 0 & 0 & 0 & 0 & 0 & 0 & 0 & 0 & 0 & 0 \\
\hline 6 & 1 & 1 & 0 & 1 & 1 & 1 & 1 & 1 & 1 & 1 & 1 & 1 & 0 & 1 & 1 \\
\hline 7 & 1 & 1 & 0 & 1 & 1 & 1 & 1 & 1 & 0 & 1 & 0 & 1 & 0 & 1 & 1 \\
\hline 8 & 1 & 0 & 1 & 0 & 0 & 0 & 0 & 1 & 0 & 1 & 0 & 1 & 0 & 0 & 0 \\
\hline 9 & 1 & 0 & 1 & 1 & 0 & 1 & 1 & 1 & 0 & 1 & 0 & 0 & 1 & 1 & 0 \\
\hline 10 & 1 & 0 & 0 & 0 & 0 & 1 & 0 & 1 & 1 & 1 & 1 & 0 & 1 & 0 & 1 \\
\hline 11 & 0 & 0 & 0 & 0 & 0 & 1 & 0 & 1 & 1 & 1 & 1 & 0 & 0 & 1 & 0 \\
\hline 12 & 1 & 1 & 0 & 0 & 1 & 1 & 1 & 1 & 1 & 0 & 0 & 1 & 0 & 1 & 1 \\
\hline 13 & 1 & 1 & 0 & 0 & 0 & 1 & 0 & 1 & 0 & 1 & 1 & 1 & 0 & 1 & 1 \\
\hline 14 & 1 & 1 & 1 & 1 & 1 & 1 & 1 & 1 & 1 & 1 & 0 & 0 & 0 & 1 & 1 \\
\hline 15 & 1 & 1 & 0 & 1 & 1 & 0 & 1 & 0 & 1 & 1 & 1 & 1 & 0 & 0 & 1 \\
\hline 16 & 0 & 1 & 0 & 1 & 1 & 1 & 0 & 0 & 1 & 1 & 0 & 1 & 1 & 0 & 1 \\
\hline 17 & 0 & 1 & 1 & 1 & 1 & 1 & 0 & 0 & 0 & 1 & 0 & 0 & 1 & 1 & 1 \\
\hline 18 & 0 & 0 & 0 & 0 & 0 & 0 & 0 & 0 & 0 & 0 & 0 & 0 & 0 & 0 & 0 \\
\hline 19 & 1 & 1 & 0 & 1 & 1 & 1 & 1 & 1 & 1 & 1 & 1 & 1 & 1 & 1 & 1 \\
\hline \multirow[t]{2}{*}{20} & 1 & 1 & 0 & 0 & 1 & 1 & 1 & 1 & 0 & 1 & 1 & 1 & 1 & 1 & 1 \\
\hline & 13 & 13 & 4 & 9 & 11 & 15 & 9 & 13 & 8 & 15 & 10 & 12 & 5 & 13 & 14 \\
\hline
\end{tabular}

Table 1. Multiple Choice Test

\section{The Percentage of The Students Score}

For the score of every student, the writer uses this formula :

$$
P=\frac{F x}{N} \times 100
$$

Where, $\mathrm{P}=$ Presentation of Score $\mathrm{Fx}=$ the frequency of all answers $\mathrm{N}=$ total number of test The table below shows the percentage of the result of the test 
Table 2. Total of Right Answers

Student(Respondents)

\begin{tabular}{|c|c|c|c|c|c|c|c|c|c|c|c|c|c|c|c|c|}
\hline Question & $P$ & Q & $\mathrm{R}$ & $\mathrm{S}$ & $\mathrm{T}$ & $U$ & V & W & $\mathrm{x}$ & $\mathrm{Y}$ & Z & AA & BB & $\mathrm{CC}$ & DD & Total of Right Answers \\
\hline 1 & 1 & 1 & 0 & 0 & 0 & 0 & 0 & 1 & 0 & 0 & 0 & 1 & 1 & 1 & 1 & 14 \\
\hline 2 & 0 & 1 & 0 & 1 & 0 & 1 & 0 & 1 & 1 & 1 & 0 & 0 & 1 & 1 & 0 & 13 \\
\hline 3 & 1 & 1 & 1 & 1 & 0 & 0 & 1 & 1 & 1 & 1 & 0 & 1 & 1 & 1 & 1 & 23 \\
\hline 4 & 1 & 1 & 0 & 0 & 0 & 0 & 0 & 0 & 1 & 1 & 0 & 0 & 1 & 1 & 1 & 12 \\
\hline 5 & 1 & 0 & 0 & 1 & 0 & 0 & 0 & 1 & 0 & 0 & 0 & 0 & 0 & 0 & 0 & 3 \\
\hline 6 & 1 & 1 & 1 & 0 & 1 & 1 & 1 & 1 & 0 & 0 & 1 & 1 & 1 & 0 & 1 & 24 \\
\hline 7 & 1 & 1 & 1 & 1 & 1 & 1 & 0 & 1 & 1 & 1 & 1 & 1 & 1 & 1 & 1 & 25 \\
\hline 8 & 1 & 0 & 0 & 0 & 0 & 0 & 0 & 1 & 0 & 0 & 0 & 0 & 0 & 0 & 1 & 8 \\
\hline 9 & 0 & 1 & 1 & 1 & 0 & 1 & 1 & 1 & 0 & 0 & 1 & 0 & 1 & 1 & 0 & 18 \\
\hline 10 & 1 & 1 & 0 & 0 & 1 & 1 & 0 & 1 & 1 & 1 & 0 & 1 & 1 & 0 & 1 & 18 \\
\hline 11 & 0 & 1 & 0 & 1 & 0 & 0 & 0 & 1 & 0 & 0 & 1 & 0 & 0 & 1 & 0 & 11 \\
\hline 12 & 0 & 1 & 1 & 1 & 1 & 1 & 1 & 1 & 1 & 1 & 1 & 1 & 1 & 0 & 0 & 22 \\
\hline 13 & 0 & 1 & 1 & 1 & 0 & 0 & 1 & 0 & 0 & 0 & 1 & 0 & 0 & 0 & 1 & 15 \\
\hline 14 & 1 & 1 & 0 & 1 & 1 & 1 & 1 & 1 & 1 & 1 & 1 & 1 & 1 & 1 & 1 & 26 \\
\hline 15 & 0 & 0 & 0 & 0 & 0 & 1 & 1 & 1 & 1 & 1 & 0 & 1 & 1 & 0 & 1 & 18 \\
\hline 16 & 0 & 1 & 1 & 1 & 0 & 1 & 0 & 1 & 1 & 1 & 1 & 0 & 1 & 0 & 1 & 19 \\
\hline 17 & 0 & 1 & 1 & 0 & 0 & 0 & 0 & 1 & 1 & 1 & 1 & 0 & 1 & 1 & 1 & 18 \\
\hline 18 & 0 & 0 & 0 & 0 & 0 & 0 & 0 & 0 & 0 & 0 & 0 & 1 & 0 & 0 & 0 & 1 \\
\hline 19 & 1 & 1 & 1 & 1 & 1 & 1 & 1 & 1 & 1 & 1 & 1 & 1 & 1 & 1 & 1 & 29 \\
\hline \multirow[t]{2}{*}{20} & 1 & 1 & 1 & 1 & 1 & 1 & 1 & 1 & 1 & 1 & 1 & 1 & 1 & 0 & 1 & 26 \\
\hline & 11 & 16 & 10 & 12 & 7 & 11 & 9 & 17 & 12 & 12 & 11 & 11 & 15 & 10 & 13 & \\
\hline
\end{tabular}

Table 3. Score and Criteria

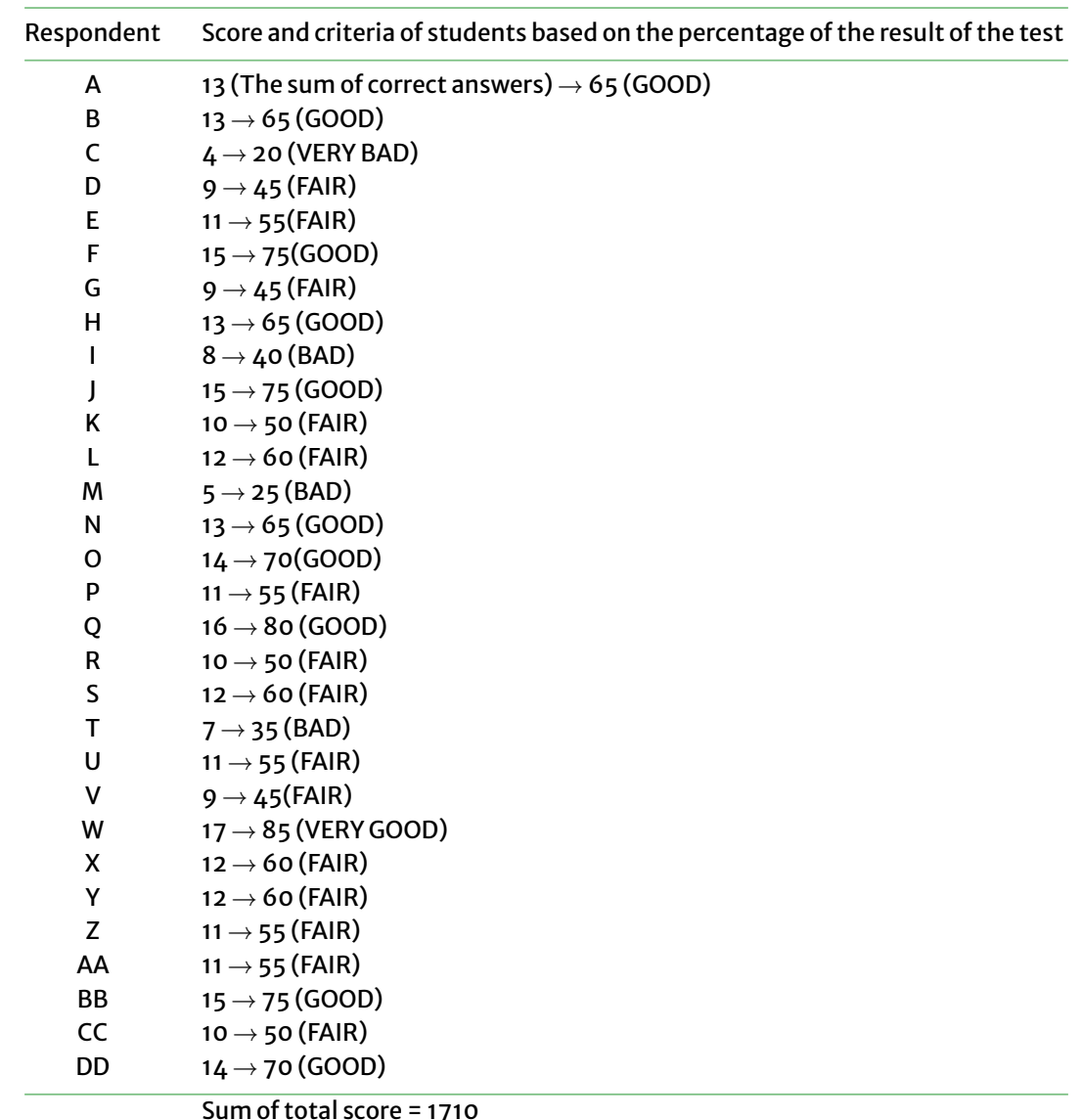

To determine the mean score, the writer uses the formula:

$$
M=\frac{F}{N} \times 100
$$


Where, $\mathrm{F}=$ sum of total score $\mathrm{N}=$ total of score $\mathrm{M}=$ mean score So,

$$
\begin{gathered}
M=\frac{1710}{30} \times 100 \\
M=57
\end{gathered}
$$

\section{Discussion}

\section{Student's Ability}

After analyzing the data, the writer presents the result in the table. Then, the writer classifies them into 5 criteria. Those criteria are:

- Very Good 81 - 100

- Good $61-80$

- Fair $41-60$

- Bad $21-40$

- Very Bad 0 - 20

The data above shows that only one student got 'very good, ten students got 'good', fifteen students got 'fair', three students got 'bad' and only one student got 'very bad' and the mean score of all students is $57 \%$. It shows that the ability of English department students batch 2017 is still low. Based on the criteria above, it can be categorized as "fair".

\section{Student's Perspective}

From questionnaires that have been given, most of the students said that English idiomatic expression is difficult to understand. Most of them are confused in understanding idiomatic expressions because the idiom words are contradicted to the real meaning of the words literally. For example, the black sheep in the family means the one who has a bad reputation in the family and keeps an eye on which means observing something.

On other hand, most the students realize that English idiomatic expressions are important to learn for some reasons such as it is used it improves knowledge and vocabulary, it is used by English native speakers in their daily life and other foreigners, it is used in drama and poetry and it is also found in many films or music. But there is also one of them said that learning English idiomatic expression is not really important without any reason and three students did not answer it. Lastly, most of the students said that they never get material about English idiomatic expression in their class even if they got such material but they just got the material very little and not all the time. Even there is a student who needs to see a dictionary if she wants to know about the idiomatic expressions and four students did not answer it.

\section{Conclusion}

Based on the analysis method in the previous chapter, the writer can conclude that English department students batch 2017 at Hasanuddin university are enough in figuring out English idiomatic expressions and it can be categorized as "Fair", with the total percentage of $57 \%$. The data shows that only one student got 'Very Good' with the percentage of $81-100 \%$, ten students got "Good" with the percentage of $61-80 \%$, fifteen students got 'fair' with the total percentage of $41-60 \%$, three students got 'bad' with the score of $21-40 \%$ and one student got 'very bad' with the percentage of $0-20 \%$.

According to the questions given to the students about the difficulties and perspectives in learning idiomatic expressions, it can be seen the difficulties faced by the students, their perspective on learning idiomatic expressions, and whether or not they have ever got such material from their lectures. The difficulties faced by the students to understand idiomatic expression because the real idiomatic expressions are contradicted to the real meaning of that sentence literally so it confuses them sometimes and their perspective on learning English idiomatic expressions is they realize that English idiomatic expressions are important to learn because it is used by native speakers and also it can be found in many things such as drama, poetry, films, and music but unfortunately most of the students declare that they never get the material about English idiomatic expression from the lectures in their class although they get material they get it very little and not all the time.

\section{References}

[1] L. S. Vance. Something to Crow About: A Concise Collection of American English Idioms For Everyday Use. Washington D.C. : Materials Development and Review Branch, 1993. 
[2] S. Hornby. Definition of Speaking Skill. New York, 1995

[3] M. J. Lado. Ungkapan Kata Kerja dan Idiom (Phrasal Verbs and Idioms). Jakarta: PT. Gelora Aksara Pratama, 1989.

[4] R. Moon. Fixed Expressions and idioms in English: A Corpus-Based Approach. USA: Oxford University Press, 1998.

[5] Grant, Lynn, Bauer, \& Laurie, Criteria for Redefining Idioms: Are We Barking up The Wrong Tree?. 2004

[6] R. A. Spears. Dictionary of American Idioms and Phrasal Verbs. New York: McGraw-Hill, 2004

[7] R. Gholamrez. "The Effect of Context on the EFL Learner's Idiom Processing Strategies," English Language Teaching, vol. 5, no. 9, 2012.

[8] Blaxter, Hughes, Tight. How to Research. Open University Press, 2006.

[9] P. Leedy \& J. Ormrod. Practical Research: Planning and Design, $7^{\text {th }}$ ed. Upper Saddle River, NJ: Merrill Prentice Hall. Thousand Oaks: SAGE Publications, 2001.

[10] Sugiyono. Metode Penelitian Kuantitatif Kualitatif dan R\&B. Bandung: Alfabeta, 2012. 